\begin{tabular}{|c|c|c|c|c|c|c|}
\hline \multirow{4}{*}{ Impact Factor: } & ISRA (India) & $=3.117$ & SIS (USA) & $=0.912$ & ICV (Poland) & $=6.630$ \\
\hline & ISI (Dubai, UAE & $=0.829$ & РИНЦ (Russia & $=0.156$ & PIF (India) & $=1.940$ \\
\hline & GIF (Australia) & $=0.564$ & ESJI (KZ) & $=8.716$ & IBI (India) & $=4.260$ \\
\hline & JIF & $=1.500$ & SJIF (Morocce & $=5.667$ & OAJI (USA) & $=0.350$ \\
\hline
\end{tabular}

\begin{tabular}{|c|c|}
\hline $\begin{array}{l}\text { SOI: } \frac{1.1 / \mathrm{TA}}{\text { International Sc }} \\
\text { Theoretical \& A }\end{array}$ & $\begin{array}{l}\text { IS DOI: } 10.15863 / \mathrm{TAS} \\
\text { cientific Journal } \\
\text { aplied Science }\end{array}$ \\
\hline p-ISSN: 2308-4944 (print) & e-ISSN: 2409-0085 (online) \\
\hline Year: $2019 \quad$ Issue: 06 & Volume: 74 \\
\hline Published: 30.06 .2019 & http://T-Science.org \\
\hline
\end{tabular}

SECTION 21. Pedagogy. Psychology. Innovations in the field of education.
QR - Issue

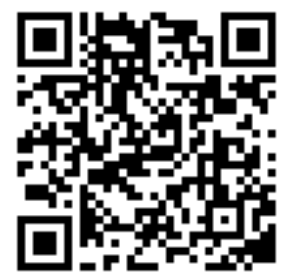

QR - Article

UDC 378.1

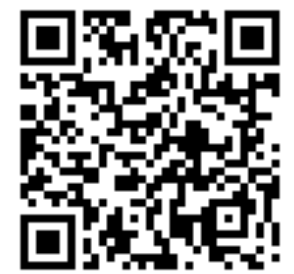

Aliboi Ergashovich Parmanov Tashkent Institute of Textile and light industry Candidate of Pedagogical Sciences, Associate Professor Tashkent city, the Republic of Uzbekistan

Otabek Alisherovich Salimov Tashkent Institute of Textile and light industry Assistant Tashkent city, the Republic of Uzbekistan

\title{
EDUCATION MANAGEMENT BY MEANS OF PEDAGOGICAL TECHNOLOGIES
}

\footnotetext{
Abstract: The article analyzes the role and importance of education management through the use of modern technologies in our country.

Key words: innovative technologies, education, management, education, teaching and educational processes.

Language: Russian

Citation: Parmanov, A. E., \& Salimov, O. A. (2019). Education management by means of pedagogical technologies. ISJ Theoretical \& Applied Science, 06 (74), 230-232.

Soi: http://s-o-i.org/1.1/TAS-06-74-26 Doi: crossef https://dx.doi.org/10.15863/TAS.2019.06.74.26

\section{УПРАВЛЕНИЕ ОБРАЗОВАНИЕМ ПОСРЕДСТВОМ ПЕДАГОГИЧЕСКИХ ТЕХНОЛОГИЙ}

Аннотация: B статье анализируется роль и важность управления образованием посредством использования современных технологий в нашей стране.

Ключевые слова: инновационные технологии, образования, управления, воспитания, учебновоспитательные процессы.
}

\section{Introduction}

Появление высокоразвитых технологий в XX1 веке и в результате их усложнённости делают жизненно важным обеспечение безопасности жизни. Уместно обратить внимание на неотложные задачи, выдвинутые Президентом Республики Узбекистан Ш.М.Мирзиёевымв его обращениях к Олий Мажлису. В частности, в своем обращении к Олий Мажлисуот 28 декабря 2018 года президент призвал продвигать инновационные образовательные технологии в процессе высшего образования на более высокий уровень [1, 136].

Процесс высшего образования предполагает использование инновационных технологий, их высокий уровень интенсификации, реализацию соответствующих мер, а также создание инновационных подходов, научных разработок и современных технологий от каждого члена нашего общества. Как сказал наш уважаемый глава государства: «Создание инновационной среды в мировозрениях наших людей является нашим главным приоритетом. Без инноваций не будет ни в одной области ни развитие ни конкуренции. Если мы не будем широко пропагандировать изменения в этой области народу, если у нас не будут человеческих навыков, то мы не сможем внести свой вклад в беспрецедентные достижения науки и техники.

\section{Materials and Methods}

Сегодня современные инновационные технологии в управлении высшим образованием являются одной из наиболее широко используемых технологий. А это является непосредственным выражением государственной политики в сфере управления высшим образованием в соответствии с Законом Республики Узбекистан «Об образовании» и «Национальной программой подготовки кадров». 


\begin{tabular}{|c|c|c|c|c|c|c|}
\hline \multirow{4}{*}{ Impact Factor: } & ISRA (India) & $=3.117$ & SIS (USA) & $=0.912$ & ICV (Poland) & $=6.630$ \\
\hline & ISI (Dubai, UAI & $=0.829$ & РИНЦ (Russia & $=0.156$ & PIF (India) & $=1.940$ \\
\hline & GIF (Australia) & $=0.564$ & ESJI (KZ) & $=8.716$ & IBI (India) & $=4.260$ \\
\hline & JIF & $=1.500$ & SJIF (Morocco & $=5.667$ & OAJI (USA) & $=0.350$ \\
\hline
\end{tabular}

Развитие профессионального и высшего образования все больше объединяет их цели и задачи.

Современные инновационные технологии в управлении высшим образованием должны обеспечить единую государственную политику в области образования и воспитания гармонично развитого поколения, обеспечить своевременное и творческое решение созревщих проблем и обеспечить, чтобы эффективность работы всех образовательных учреждений отвечали их современным требованиям.

Вместе с тем это является задачей всех правительственных и общественных организаций, это, естественно, сложный процесс, прежде всего требующий всестороннего пересмотра содержания деятельности учреждений непрерывного образования. Все это имеет особое значение в управлении и развитии высшего образования. Для этого управление и развитие образования могут быть организованы в установленном порядке за счет юридических и физических лиц, в том числе за счет добровольных взносов иностранных юридических и физических лиц.

Министерство высшего и среднего специального образования управляет и руководит всеми университетами, профессиональными колледжами, лицеями и учебными заведениями. Разрабатывает и утверждает учебные планы и программы для высшего и профессионального образования.

Управление высшим образованием заранее планируется сверху вниз в сочетании с процессами работы во всех сферах образования, определяя содержание работы всех учебных заведений. В процессе управления широко используются различные инновационные методы. Правильное внедрение инновационных технологий в учебно-воспитательные процессы может привести учителя к работе в качестве основного организатора или консультанта в этом процессе. Это создает формирование большой самостоятельности, креативности и воли у студентов, а проведенные занятиясоздают для студентов выразить свои отношения к важным жизненным достижениям и проблемам молодёжи и требуют их самостоятельного осмысления [2].

.В современных инновационных процессах происходящие в текущем периоде нужны люди которые способны самостоятельно и свободно мыслить, принимать необходимые решения, владеть новой информацией для решения проблем в системе образования, самостоятельно оценивать эту информацию. В связи с этим роль и значение высшего образования в процессе управления инновационными технологиями неизмеримы. Инновация (по английский innovation) - это означает нововведение, новшество.
Инновационные технологии - это педагогический процесс, а также введение инновации и изменения в творческую деятельностьмежду учителем и учеником, а при его реализации используются интерактивные методы, поскольку управленческую роли в образовании играет учитель.

К интерактивным методам относятся «Семинар соревнования», технология «Знакомство», технология “Ступеньки”, технология «Мозговой штурм», технология «Круговорот», технология «Кластер», технология «Бумеранг», технология «3x4», технология «Резюме», «Технология проблем», «Технология лабиринта», «Методы блиц-опроса», технология «Техника ФГМУ», технология «Скарабея», технология «Веер», технология «Диалог», технология «Спор», технология «Сценарий» и другие [3].

Например, организация урока по технологии “Семинар соревнования” широко используется в образовании на протяжении многих лет. Этот метод повышает интерес и активность студентов. Для того, тобы подготовиться к этому методу заранее предупреждают студентов, и тема объявляется заранее. Студенческая группа подразделяется на две подгруппы. Каждый из них должен подготовить вопрос по теме. В начале семинара студенты будут ознакомлены с условиями конкурса. Здесь даются определённые баллы не только за ответы, но из за правильность и точность вопросов, а также за дополнения и поправки. Всемстудентам группы могут быть предоставлены минусовые баллы за активное участие, например, могут использоваться метод вычитания балловот +3 до -3 за неправильные ответы и вопросы. Набранные баллы во время соревнования, могут быть записаны на доске. В конце семинара группу победителей можно поощрять дополнительными баллами. Педагог, как руководитель учебного процесса, должен внимательно и бдительно слушать ответы, и оценивать каждого студента. Этот метод учит твёрже закреплять знания, повышать речевую культуру, правильно сформулировать вопросы и выражать свои мысли. И самое главное, он учит студентов самостоятельно приобретать знания, искать новости и творческий подходить к предмету. Рассматриваемая тема подробно анализируется и связывается с жизненно важными процессами. Наилучшие результаты могут быть достигнуты, если первые формы этой инновационной технологии используются в университете.

\section{Conclusion}

Метод работа в малых группах. При этом методе студенты группы подразделяются на несколько групп, в каждой группе могут быть 4-5 


\begin{tabular}{|c|c|c|c|c|c|c|}
\hline \multirow{4}{*}{ Impact Factor: } & ISRA (India) & $=3.117$ & SIS (USA) & $=0.912$ & ICV (Poland) & $=6.630$ \\
\hline & ISI (Dubai, UAE & $=0.829$ & РИНЦ (Russia & $=0.156$ & PIF (India) & $=1.940$ \\
\hline & GIF (Australia) & $=0.564$ & ESJI (KZ) & $=8.716$ & IBI (India) & $=4.260$ \\
\hline & JIF & $=1.500$ & SJIF (Morocce & $=5.667$ & OAJI (USA) & $=0.350$ \\
\hline
\end{tabular}

студентов. Назначается руководитель каждой группы. Им заранее дается задание. Группа студентов вместе готовятся к семинару и они должны постараться полностью осветить свои вопросы. Другие группы задают вопросы основному докладчику, студенты группы помогают ответить на вопросы.После защиты основного спикера оппоненты должны быть в состоянии объяснить вопрос более подробно [3]. Студенты третьей и четвертой группывыразив свое мнение, должны оценивать и комментировать работу группы, проводивщую исследование. Для того, чтобы работать таким образом, при создании групп важно, чтобы учащиеся в группах имели равные знания. При руководстве группы следует выбрать хорошо успевающего студента. После окончания такого конкурса инновационных технологий, можно проводитьи другие виды соревнований по разделу.

В это связи целесообразно организовать дидактические игры с инновационными технологиями.

\section{References:}

1. Mirziyoev, S. M. (2017). "Strategija dejstvij" pjat' prioritetnyh napravlenij razvitija v 2017 2021 godah. (p.136). Tashkent: Gafur Guljam.

2. Karimov, I. A. (2008). Vysokaja duhovnost' nepobedimaja sila. Tashkent: Ma\#navijat.

3. Ishmuhamedov, R. Z. (2005). Puti povyshenija jeffektivnosti obrazovanija s pomoshh'ju innovacionnyh tehnologij. Tashkent: TGPU.

4. Hudojkulov, H. Z. (2012). Pedagogicheskie tehnologii osnovy jeffektivnosti obrazovanija. Tashkent: Navruz.
5. Sibirskaja, M. P. (2002). Professional'noe obuchenie: Pedagogicheskie tehnologii. Sankt Peterburg.

6. Zimnjaja, I. A. (1997). Pedagogicheskaja psihologija. [Tekst]. (p.295). Rostov-na- Donu: Denisk.

7. Verbickaja, A. A. (1991). Aktivnye metody obuchenie $v$ vysshej shkole: konteksnyj podhod. [Tekst]. (pp.37-41). Moscow: Anegnaja shkola.

8. Talyzina, N. F. (2003). Pedagogicheskaja psihologija. [Tekst]. (p.63). Moscow: Akademija. 